\author{
Abstracta Iranica \\ Abstracta Iranica Revue bibliographique pour le domaine irano-aryen \\ Volume 32-33 | 2013 \\ Comptes rendus des publications de 2009-2010
}

\title{
Parthica - Incontri di culture nel mondo antico - Afghanistan. I tesori ritrovati
}

\section{Carlo Lippolis}

\section{(2) OpenEdition \\ 1 Journals}

\section{Electronic version}

URL: http://journals.openedition.org/abstractairanica/40729

DOI: 10.4000/abstractairanica.40729

ISSN: 1961-960X

Publisher:

CNRS (UMR 7528 Mondes iraniens et indiens), Éditions de l'IFRI

\section{Printed version}

Date of publication: 1 December 2013

ISSN: 0240-8910

\section{Electronic reference}

Carlo Lippolis, « Parthica - Incontri di culture nel mondo antico - Afghanistan. I tesori ritrovati », Abstracta Iranica [Online], Volume 32-33 | 2013, document 20, Online since 01 July 2016, connection on 27 September 2020. URL : http://journals.openedition.org/abstractairanica/40729 ; DOI : https:// doi.org/10.4000/abstractairanica.40729

This text was automatically generated on 27 September 2020.

Tous droits réservés 


\title{
Parthica - Incontri di culture nel mondo antico - Afghanistan. I tesori ritrovati
}

\author{
Carlo Lippolis
}

\section{REFERENCES}

Parthica - Incontri di culture nel mondo antico - Afghanistan. I tesori ritrovati. Vol. 11, Pisa-

Roma, Accademia Editoriale, 2009, 141 p., num. figs. in the text, VIII colour pls.

1 The 2009 (11th) issue of the journal Parthica contains papers presented at the international conference held in Turin on 24 October 2007 on the occasion of an exhibition at the Museo di Antichità di Torino organized by the Fondazione per l'Arte della Compagnia di San Paolo. It contains contributions from: P. Cambon ("Le Musée Guimet et l'Afghanistan"), S. Saifi ("Testimonianze dal Museo di Kabul”), P. Bernard ("La découverte et la fouille du site hellénistique d'Ai Khanoum"), A. Filigenzi ("La Missione Archeologica Italiana in Afghanistan dell'IsIAO"), G. de Palma ("Intervento italiano dell'ISCR nella conservazione per il Museo di Kabul"), A. Invernizzi (“Arte ellenistica in Asia Centrale), F. Coarelli (Ritorno a Begram"), A. Santoro ("Influssi di cultura indiana"), V. Schiltz ("L'art nomade à Tillia Tepe"), and Paola Piacentini (“Arte iranica e produzione orafa a Tillia Tepe"). 


\section{AUTHORS}

\section{CARLO LIPPOLIS}

Università di Torino 